\begin{tabular}{|c|c|c|}
\hline \hline & $\begin{array}{c}\text { Mansoura University } \\
\text { Faculty of Engineering } \\
\text { Mansoura Engineering Journal }\end{array}$ & 0 \\
& 0 & 0 \\
\hline
\end{tabular}

\title{
Public spaces in City life as Socio-cultural Hubs. Selected Public Spaces of Cairo as Case studies.
}

\author{
Ahmed Hosney Radwan and Ahmed Abdel Ghaney Morsi
}

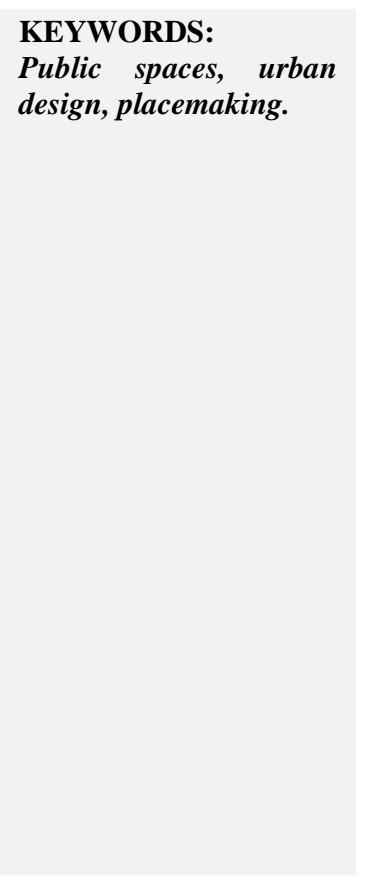

\begin{abstract}
It is always essential for all public spaces to incorporate various factors that help any public space play its vital role in the City, including quality, quantity, accessibility, and connectivity of such spaces to their local communities. This Paper Investigates the vital role of Public Spaces as Sociocultural Hubs needed for society's well-being, especially in metropolitan cities. With an essential question of developing such spaces as multi-purpose and critical challenges, such spaces are supposed to adapt to their cultural \& environmental contexts, thus leading to better socio-cultural interaction. Fulfilling The critical use of public space where people can enjoy their social life and co-existence, representing their interests so that nothing is disaggregating or drowning for their diversity. The Paper also sheds light on public spaces' failure to get proper attention despite their importance. A literature overview is done for public spaces, with a focus on the UN habitat in collaboration with other partner institutions toolkit of Global public space as a user-friendly guide, and how to improve the quality and distribution of public spaces and how to make them available and accessible for the public in addition to the practice guidelines. This Paper highlights the need for Public Spaces in Cairo, Urban Challenges in this concern, and how proper actions and measures should be taken. Policies can be made accordingly for the public space developmental plans in Cairo. Considering the urgent need for Public spaces That widely reflect such Rich and diversified culture and Local Identity, the Paper ends with some suggested guidelines based on the Theoretical review and Analytical studies, in addition to some Recommendations.
\end{abstract}

\section{INTRODUCTION.}

$\mathrm{P}$ UBLIC Spaces of the City are considered as Physical Container of various Cultural Practices of City Residents, where it is hard to separate the Physical features of these spaces from such practices and lifestyles. Public spaces should also provide its users with what makes them belonging to it, where they spend as much time as possible within these spaces, whether during Daytime, on their way to work from home or vice versa, after work times, or during weekends, holidays, etc.

Received: (5 November, 2020) - Revised: (25 November, 2020) Accepted: (30 November, 2020)

Corresponding Author: Ahmed Hosney Radwan, Associate Professor of Architecture \& Urban Design, Department of Architecture, Faculty of Fine Arts, Helwan University, Cairo, Egypt. Email: ahosney@gmail.com,ahosney@f-arts.helwan.edu.eg.
Many elements are integrated to fulfill such objectives, starting from the Human scale of public spaces, their surroundings, green coverages, street furniture\& StreetScapes, level of technology or smartness Applied, in addition to the social role of these spaces that are widely related to common ideologies From gender \& social equality, to economic equality, where successful public space is the one which can host all community members in a Highly efficient way.

The components of any public space is also extended to incorporate different arts that can be performed in such spaces, and how it could be allowable as a way of expressing socio-cultural values of the community,

Ahmed Abdel Ghaney Morsi., Associate Professor of Architecture \& Urban Design, Department of Architecture, Faculty of Fine Arts, Helwan University, Cairo, Egypt. Email: masterlinegroup@yahoo.com. 
whether these arts are Music, Sculptures, or other forms of Arts that reflect the local identity.

Cairo is among these Cities, with its diverse history and culture that should have Public Spaces, That widely and reflect such Rich and diversified culture and Local Identity, whether through its physical form that support the previously mentioned activities or by encouraging the community to utilize these spaces efficiently and friendly.

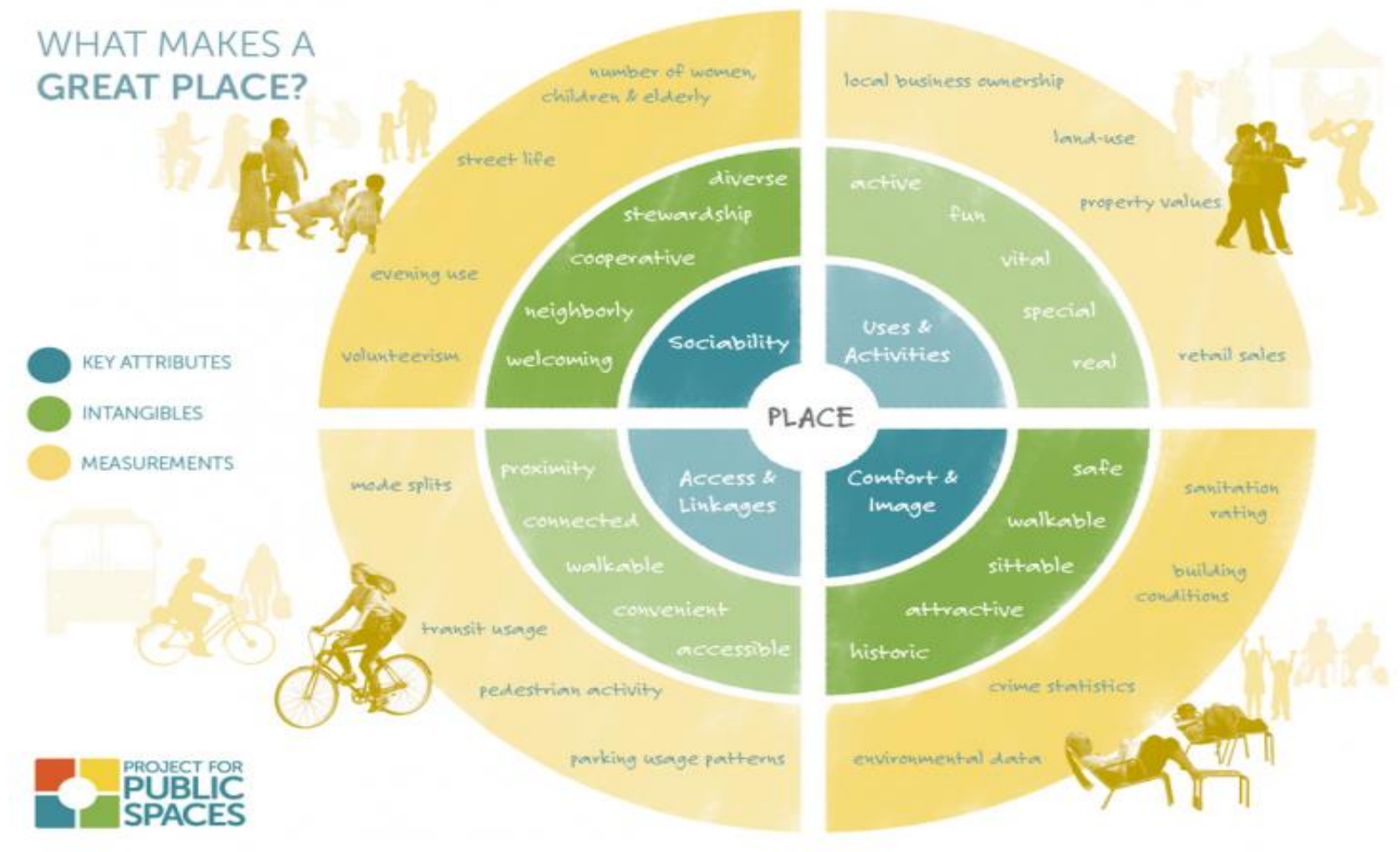

Figure 1 Attributes of functional public spaces (c) Project for Public Spaces. Source (http://www.pps.org).

\section{Problems Related to Research:}

a) Cairo and its need for public spaces:

When there is a growth in cities, there is a need to access the pleasant and captivating public spaces due to population densification. The presence of public spaces is needed for a better cultural environment. The public spaces need Priority-based attention in major cities of the world since all the city residents use these public spaces. Since these public spaces provide an ideal opportunity for socializing and community mix up, they are needed in major cities. It is a form of attention and cares the local bodies provide to the people of their areas. There is a clear and evident lack of public realm in the Egyptian capital city, Cairo, and space is needed for all the community members living in the City. Cairo's public spaces represent contested spatial, social, and symbolic configurations, and all these are the outcomes of enhancing the urban fabrics multiplicity. Debating about the production of the public space, one question is often asked in genuine, and the question is, in the formation of successful public places or people scaled places, what is involved? Are the designs supposed to promote public relations, or do the social initiatives likely to produce highly successful public spaces? In case of loss of these successful public spaces, who is suffering?

Do the sufferings are common for all the society, or only the urban low class is affected. For prosperous cities, public spaces are vital elements. Social capital and financial growth are ensured and facilitated by public spaces. Also, these public spaces help in the revitalization of the communities. The easy access promotes the quality and standard of life to the public spaces, but these public spaces are also regarded as the initial step to citizen empowerment. In this way, the public also has greater access to institutional and political spaces. All public spaces, liveliness, and continuous usage are ideal ways to make a healthy urban environment. This ultimately helps to create a society that is well maintained, cooperative, and healthy. These public spaces also make the cities more attractive, and people love to settle in such cities.

b) Cairo and its Urban challenges regarding public spaces.

There is an apparent lack of public spaces in Cairo, and such venues are missing from the City for the community members (Attia, S 2011). There are several communitybased groups and classes where Cairo citizens are generally divided, and they are placed into these separate realms. This socio-spatial distribution creates a separate identity to recognize the larger communities and their social levels. Consequently, by diversified ideologies, the urban public spaces are under challenge, which ultimately results in the decline of public space utilization.

\section{OBJECTIVES OF RESEARCH:}

The public spaces in Cairo are studied in this Paper. The main aim of this investigation is to determine the demographic, social, and geographical features of the 
City's public spaces. The location (rural, urban or suburban, downtown, etc.), architecture, financial development, social communities, connectivity, ethnic diversity are considered for the functionality. It is also yet to be determined in this Paper whether there is any specific planning or designing initiative leading to the maintenance of public spaces in the City or whether the public spaces have been shaped more organically and lack structured planning.

\section{THE METHODOLOGY OF RESEARCH.}

The current situation of public spaces is highlighted in Cairo, and the research methodology includes all the observation regarding the existing problems in attracting the public to the public spaces:

a) Analytical study based on Case studies, experiences, and general analysis.

Some international, regional, and other local examples are reviewed in this analytical approach to better public spaces in Cairo. Hence, the discussions are made in the end regarding the challenges which are being faced in this Research and its limitations.

\section{b) Suggestions, throughout the applied study}

For the Architects, urban planners, this Research must end with specific conclusions. Some suggestions are also needed for the inhabitants to use and implement this Research for future investigative work.

\section{LITERATURE REVIEW:}

One of the main questions here is, what are the public spaces? This question should be asked before the collection of any data and making any analysis. You can find many answers while going through this question, and some of the central answers you are more likely to find include:

"The places used by the public and these are often termed as publicly owned places, these are enjoyable and easily accessible to the public and are free of cost and no profit motive is there behind the planning of these places.
Various public spaces include spatial forms, parks, streets, sidewalks, and footpaths connecting the people. Public spaces also include markets, malls, recreation, and border spaces between two buildings. Some roadsides are often termed as public spaces since they are essential for poor people living in cities. Besides, beaches are also included in public spaces in many contexts. The term open spaces could not be used by the public spaces even though some open spaces like the library, schools, and markets are publicly owned, and hence they are regarded as open spaces owned by the public.

\section{A Public Space definition:}

Space that is open and accessible to the people is known as a public space. There are so many things included in the public spaces, such as pavements and roadsides, gardens and parks, public squares, and beaches included in public spaces. Some government buildings are also included under the public spaces, such as libraries though limited areas of these places and usage are limited. Some privately owned buildings and other properties, although they are not considered as public spaces, they play a significant role in the visual landscape of the public; outdoor advertising is an example of it. In recent times, the shared space concept has been introduced, and it has advanced to promote pedestrians' public space experience. This space is considered to be used the automobiles and other moving vehicles collectively. The public spaces' infield of philosophy has also become a touchstone and visual arts, geography, cultural-based studies, urban designing, and social studies. The public space is a word which is sometimes misconstrued to mean a different kind of things such as a space to meet up which is among the social space's broader concept. For these type of public spaces commons is one of the earliest examples. No tickets or entry fee for example is taken to gain entry into these spaces. With the presence of public the non-government malls are the examples of private spaces.

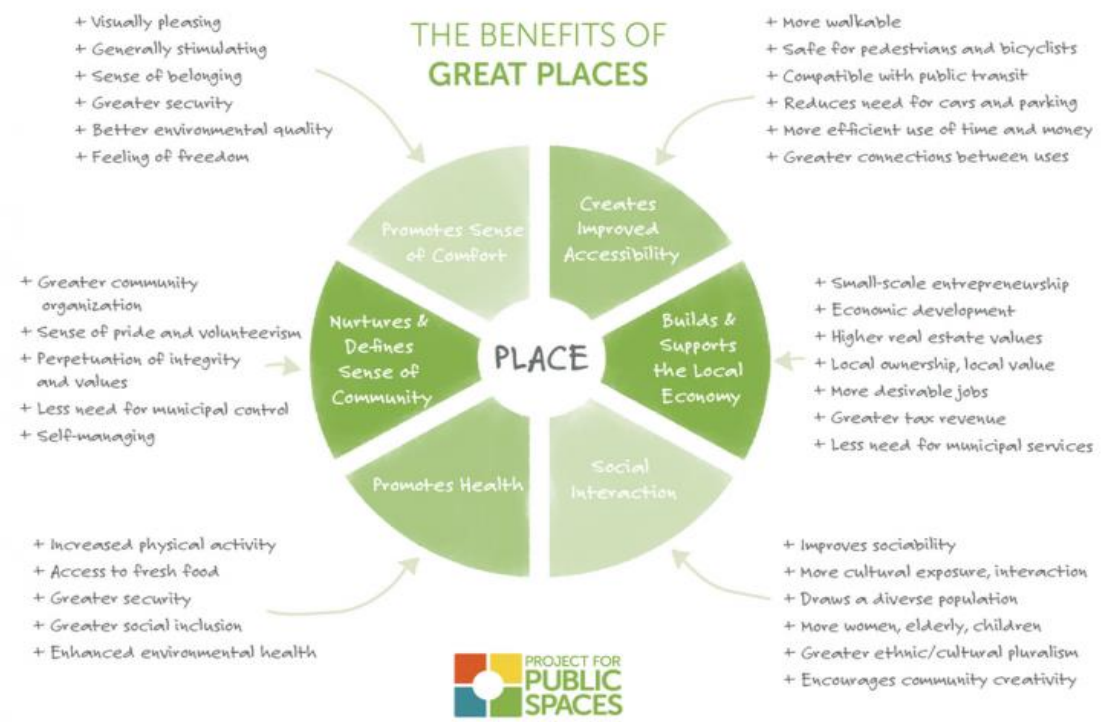

Figure 2. More than just space - quality public spaces hold significant benefits for cities(c) Project for Public Spaces. Source (http://www.pps.org). 


\section{B The Public Space Creation:}

Simultaneously, public space creation includes and rises above specialized communication among people and their current circumstance. choices regarding configuration, financing, and the executive's contemplations. One might say that creating a public space is a mind-boggling cycle of spatial just as social setups that develop and follow social examples. Metropolitan structures are comprised of materials, volumes, tones, and statures and comprise employments, streams, recognitions, mental affiliations, and illustrative frameworks whose importance changes with time, societies, and social groups. (Lynch, 1960, referred to in Castells, 1983). Nonetheless, it is regularly discussed whether it is the plan of public spaces that energizes human flourishing or whether its prosperity relies upon individuals' contribution and consideration in open space. (2001) There are two primary cycles of progress in the portrayal of metropolitan space: ontogenetic versus phylogenetic change or spatial versus spatial advancement. Phylogenetic change or spatial development includes the advancement of spatial capacity or type. This cycle is also alluded to as a typological cycle dependent on a human concession to room utilization. As portrayed in the Kropf Conceptions of Change in the Built Environment (2001), The word type or typological component expects the structure and capacity of a general idea of a specific spatial element, which is depicted by society. This interchange between people, their thoughts, and their environmental factors show that typologies result from social propensities and social examples. The advancement of spatial typologies, along these lines, includes immediate They adjust to some ecological circumstance and hence look for the distinction to react to regular formative needs. This spatial change model underlines the social component's significance in creating a room, both the spatial structure and its representative importance. The association is liable for making dynamic mutual spaces because the room's structure and capacity straightforwardly rely upon the incorporation of shared spaces in the planning cycle. However, the complexity of the findings in today's urban landscape suggests that the social contradictions in spatial function and meaning are the basis of urban change, hindering progress while growing social and spatial fragmentation. When this relationship is compromised, the relationship between people and space determines a town's identity and image.

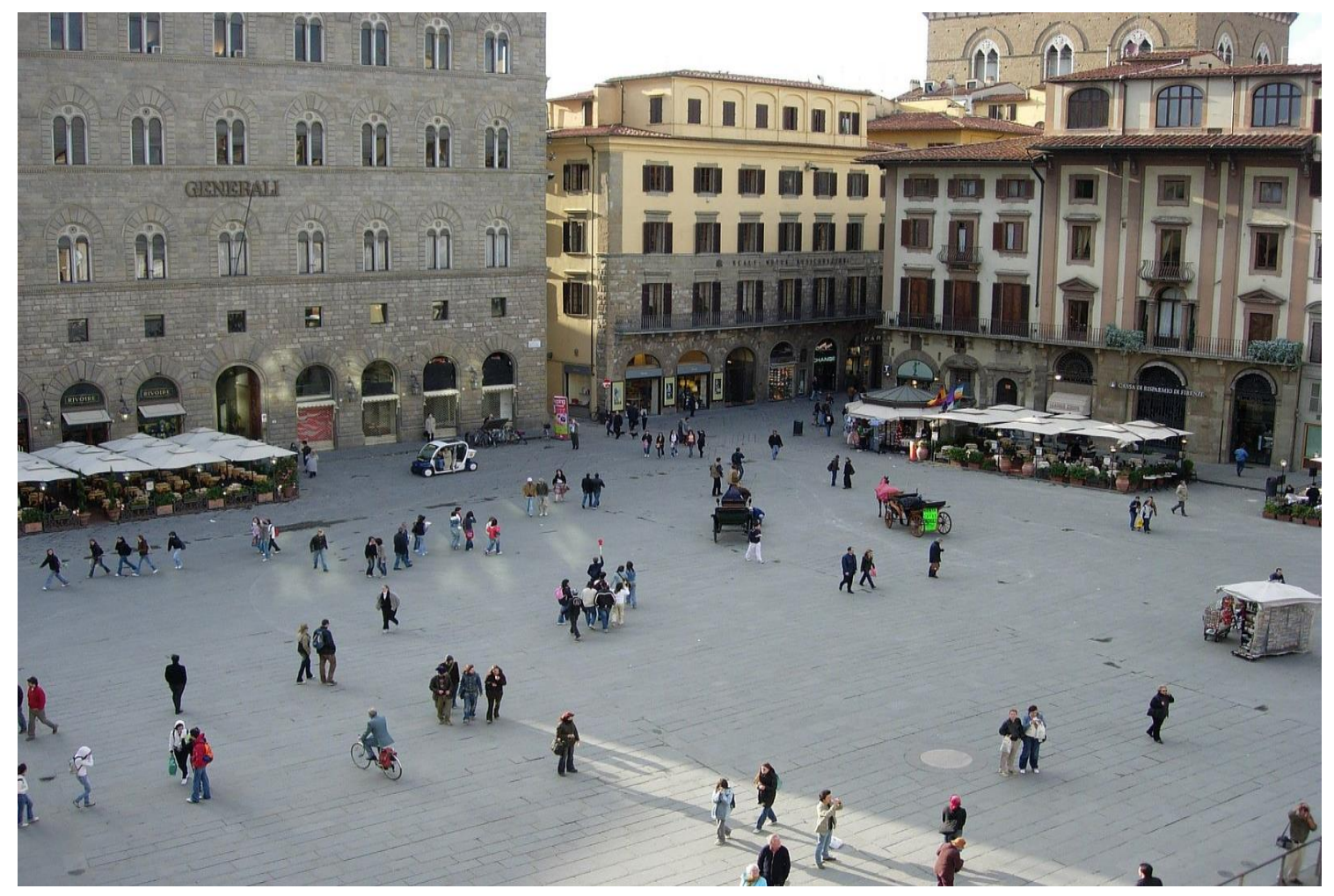

Figure 3.Piazza Della Signoria, Florence, Italy. Source: https://en.wikipedia.org

\section{i) Public Spaces-Uses.}

The usage of public spaces depends on the time of day and the day of the week and is dictated by what is provided at a given place. At the end of a day's school day in one of the town centers, older people were shopping early on in the central market, kids and youngsters were out, and young adults dominated the downtown at night.

\section{ii) Public Spaces Features and Elements.}

How does the public space capitalize on the design, scale, architecture, and proportionality of buildings to construct engaging visual experiences, views, etc.? Adapt to various applications? Suitable for multiple users? Is it reachable by foot, bike, or public transit? Environment and natural features are used, protected, and strengthened. 


\section{iii) Public Spaces\& Art.}

A sense of change describes how public art has evolved. This sense of change. Temporary art was a longstanding practice in public spaces. But the presence of public art in our contemporary cities has become more and more prevalent and essential. Public temporary art is so significant in its capacity for sensitivity, reflection, and discovery of the contexts in which it resides. The urban arts are studying, discovering, and articulating the diverse and varied public environment. Patricia Phillips explains, "the collective demand for art that is modern and contemporary reacts to and expresses its temporal and circumstantial climate." The public art invites the public to reconsider, remember, and relive. Public art asks the public to rethink. In design, the City was based on the need for fresh and innovative ways of reusing, rebuilding, and reinventing the City, in line with a growing trend in rejuvenating our cities for a sustainable future. The need to save the urban tool of an industrial, commercialized, city-leaving deathbed pit has infected contemporary design.

Inherently, art is difficult to maintain in public spaces. It is often placed outside, not in an institution such as a museum that focuses on art. It is also a matter of presentation that art occurs in public places without focusing on museums' artwork. Denmark has a public museum of art. It investigates art in public spaces and collects and exhibits, amongst other things, drawings and models. However, how is an art that is in public spaces present? Are the peasants keen to have an art experience while walking around? Digital media has enabled knowledge to be disseminated at the places where arts are experienced, and the people who aren't interested in arts are not forced to experience it. There are some online websites and Art on Site apps for this purpose. This art foundation aims to offer more knowledge, which one generally looks for availability.

\section{Public Spaces, Activities, and Sociability.}

The local nature and the community's personality and brought up are depicted by these public spaces. It is always interesting to find out the ways social interactions are enhanced by these public spaces and how they create a community sense in the surrounding areas and how it makes people comfortable and social so that they freely interact with each other especially those who come together in a diverse cross-section of the public and use space $\&$ encourage interaction.

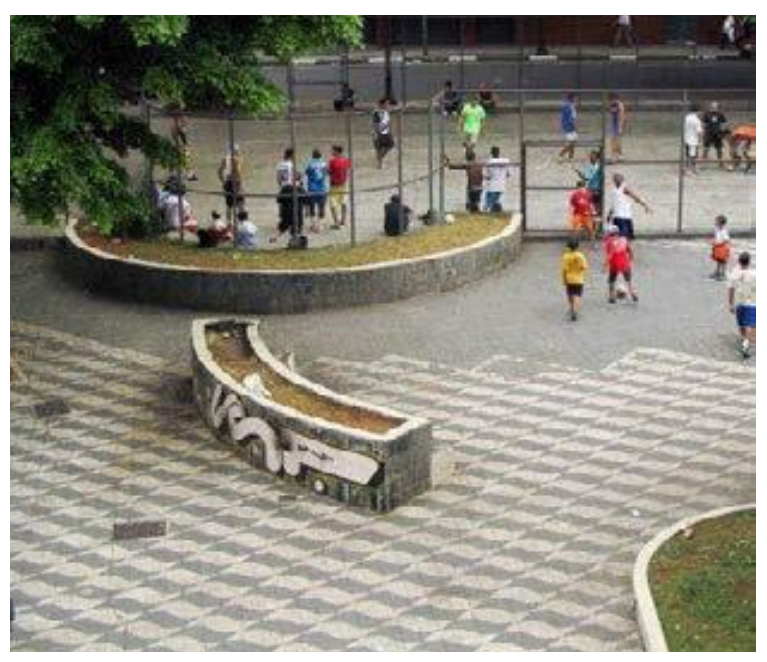

\section{Public Spaces-Social value(s).}

The high streets, markets of streets, precincts shopping, parks and playgrounds, the community centers, the surrounding or neighboring spaces, especially across the residential places, are all included in the public spaces. They play a significant role in the communities their social lives. They play the selforganizing public service act and some shared resources whereby the values are created and some good experiences as well. (Mean and Tims, 2005). Sometimes, policymakers and outsiders often lack essential evidence about public spaces' social advantages. JRF. 2007). The public spaces offer good feelings to the engaged communities, and hence it provides a sense of satisfaction to the people, which is the most significant advantage of these public spaces. The people of the cities remain busy, but they get peaceful and quality time to calm themselves at the benches in their favorite parks and places by utilizing these public spaces. These places also reflect the traditions of communities, and hence one can experience cultural diversity and learn about various cultures via these public places. Everyone has essential advantages and helps create local connections that are the core of a community sense.

\section{i) Public Spaces \& Community Participation.}

Populations have been identified as critical conditions for the success of creating and managing public spaces and the application of effective regulations. More and more cities have also chosen to play cultural roles in public spaces. Artists, designers, and urban professionals are invited to utilize interventions involving arts and urban environments, particularly in urban sprawl and development, to reinvent and regenerate public spaces. To establish community-based public space management measures, traditional and collective maintenance practices enable the population to take them over. Finally, cultural events offer the opportunity to promote or rebuild abandoned public spaces to enhance social harmony and "working together."

Many questions, such as: Who should design public space, are created in this respect? Do public spaces need to be designed? The success of public space can be measured. It is one of the most exciting questions in the mind of public space planners and designers. Without any loss of publicity, can the private sector be worried about public space provision? The availability of public space is the key, but do democracy and equality achievements depend entirely on public spaces' availability? 


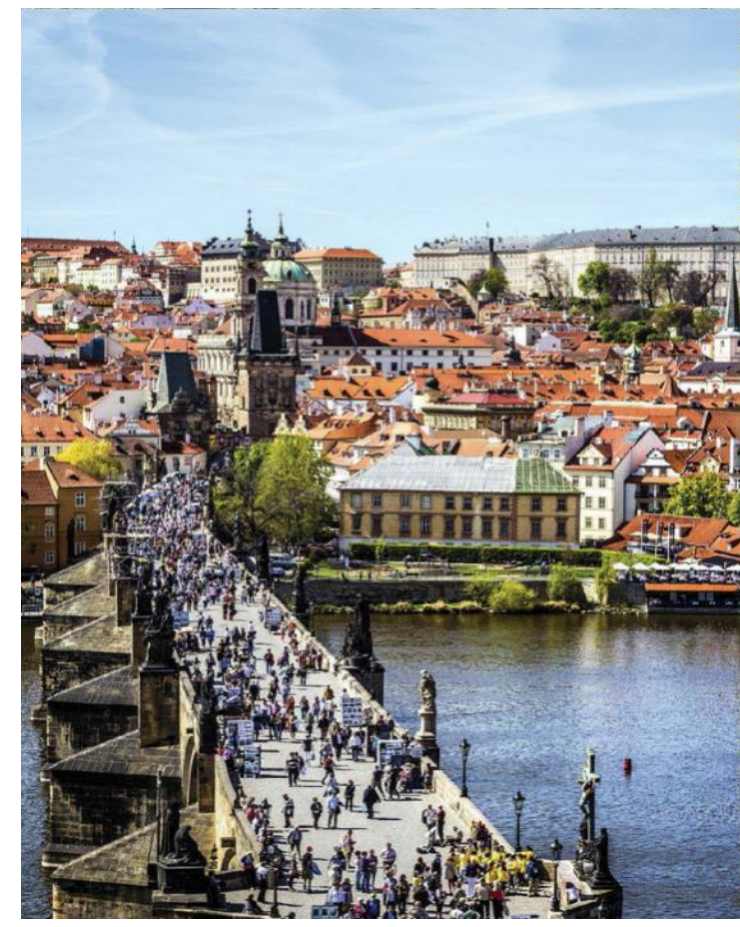

Figure 4 Charles Bridge, Prague, Republic of Czech.Source (www.myczechrepublic.com/prague).

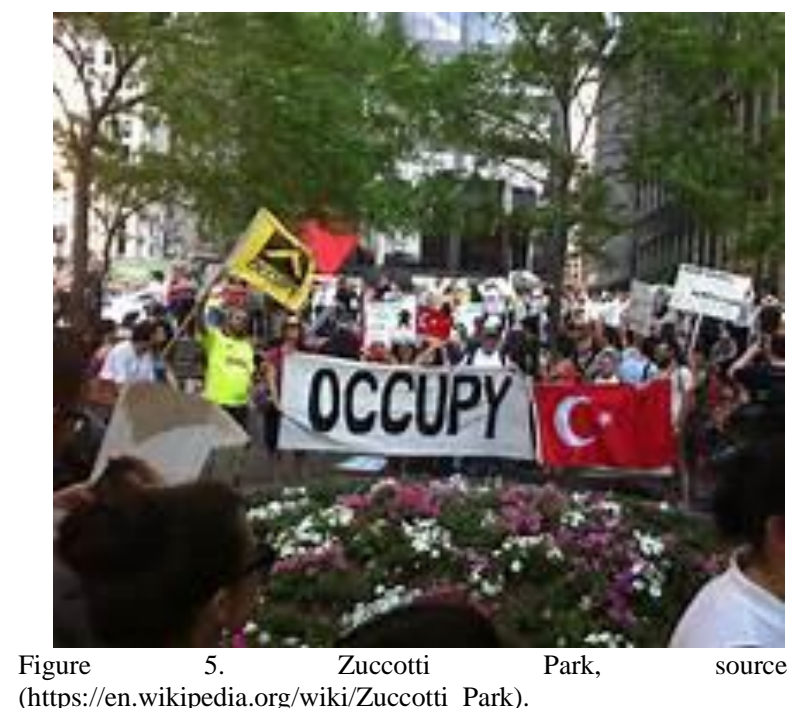

ii) Public Spaces \&Culture:

By the public spaces, the approaches for cultural development can be directly applied. In the fundamental infrastructure of urban landscaping, the public places are essential, and they highlight it via their utilization and morphology, urban spaces' historical and cultural diversity, etc. Cultural patrimony should be studied thoroughly.

Cultural patrimony should be thoroughly studied, including various cultural expressions and practices, urban morphology and architecture, etc. Therefore, the functioning of public spaces is essential to be studied for the proper planning choices and guide management. Historical traces are needed to be conserved, and the traditional practices are supposed to be maintained in the same way. It is essential to consider that there is a direct impact of cultural diversity affected by public spaces' quality and availability. In this way, social capital is developed when a proper public place is established.

In this aspect, there are several questions to be asked:

- How can the public's quality and inclusiveness be enhanced by the use of cultural and patrimonial diversity?

- How are the public spaces likely to reflect cultural diversity and urban recognition when they are nicely planned and developed?

- How can one avoid the homogenization of the public or urban spaces?

- What are the ways to enhance public spaces' ownership, especially in the areas that are not nicely planned via the identification of various expression and cultural practices?

- How can the public spaces' management and their proper functioning be enhanced via various practices of traditional management and culture?

\section{iii) The impact of political changes on the public spaces:}

This era is regarded as a digital age; high standing in the public sphere has been retained by the public spaces, especially in 2011 from Tahrir Square to Zuccotti Park, previously known as Plaza Park, some famous public spaces. They have reminded us of the potential to adjust various consequential political movements. Also, these virtual public spaces have impacted leisure activities in Lower Manhattan City. It is still a prominent place in modern times.

\section{iv) Public Spaces- between public and private.}

As previously mentioned, a public space may be a square, a bus stop, a park, or even the roads we ride from one to the next. These are areas in which we freely travel without thought. And wherever we are, we are in the public field, no doubt. But a school, a hospital or a town hall, what about? Or the local shopping center fitness center? These places can, though they are private property, also be described as public areas. The essential factor is that the space is open to all, even if the entrance fee is charged. However, they are not necessarily accessible to all in practice. You may not visit or stay freely in government ministries, hospitals, and schools if you have a reason to go to those places. Nor is it considered suitable for the homeless to settle for very long in certain areas of public space. It does not necessarily mean that space is, in fact, public in principle, in practice, always accessible to all or accessible to everyone. Many would not think it is a public space that has to be paid an entry fee-like a museum, even if it is a state museum, which belongs in principle to us all. On the other hand, many people probably regard shopping centers, although they are private, as part of the public domain.

\section{v) Public Spaces types.}

\section{(1) Streets as Public Spaces.}

The public spaces are included in the first categories that are too versatile and used extensively in our everyday lives. These public places include various famous boulevards, avenues, streets, pavements, passages, plazas, city centers, shopping malls, art galleries, paths of bicycles, etc. 
These all are publicly owned spaces, and hence these public spaces are in the fullest word sense; they are easily accessible to the public and well maintained. They are enjoyable and free of cost for the public at all hours, either day or night. In terms of public enjoyment, public spaces in this category are highly versatile. You can see plenty of activities across these public places, such as political demonstrations and rallies, art performances, open-air markets, informal activities, etc. They allow mobility, which is an essential urban function, and hence, there are multiple uses of these public spaces. For the public spaces of such kinds, the critical feature is that they are highly vulnerable to dominating users, such as motor vehicles, are more dominant than pedestrians. Hence, pedestrians' mobility is considered endangered.

\section{(2) Public Open Spaces:}

Open public spaces are included in the second category; when we think about these open public spaces, some of the urban features instinctively coming to mind are parks and gardens, children's playgrounds, riverbanks, waterfronts, beaches, etc. The public can access these all spaces free of cost, and there are no charges for these places and hence these places are publicly owned and maintained accordingly. On the other hand, there are many cases where these places are accessible during daytime only.

\section{(3) Public Urban Facilities:}

For the everyday public spaces, the third group generally comprises facilities requiring high public management so that the public owned places are maintained nicely, and all users have free access to these places. These places include community centers, public libraries, city center markets, and sports grounds facilities for public sports and leisure. There are some other cases where for a few operating hours, especially in daylight, these facilities are accessible to the general public. These nonphysical categories should be listed as well in the concept of public spaces.

\section{(4) The 'Space of the Public':}

The public space is defined as a place that is only for the use of the public. The term public here is generally not intended as a general public, but the name is given as a form of the realm of a public sector. The commons, in this sense, are merely not suitable for these social places. The public places are the areas whereby the people delegate authority and contribute to the resources in the common interest of the public places. The people of a city also show their level of trust in the officials' elected locally. On the breakdown of this social part or when this bond is compromised, this public space is particularly threatened the same way as democracy.

\section{(5) The City itself:}

The public space of a city is the second category. Since it offers a comprehensive way to public space, this holistic view is essential to the public space, and it is a good idea to name City as a public place. The right to the City is another aspect that is linked to this term and is highly debatable. In this case, the cities are generally considered arenas and expressions of symbolic space devoted to all society people and shared by the citizen of all categories. People also trust these places.

\section{(6) Cyberspace}

Cyberspace is regarded as the third nonphysical public space category. It has to be noted that the public spaces are the center of people and communities' interaction and play the role of an important place for communication. Via social media networks and the internet, cyberspace offers the latest opportunities for computer-based interactions and encounters. Hence, it can end up in real space interaction and socializing as people like minds meet and interact in real life. Sometimes, it is often under discussion that the fundamental basis of democracy is political engagements, and with the help of web technology, these interactions are greatly enhanced. While cyberspace has some limitations, there is a risk that online interaction might replace or limit people and communities' physical interaction. In this chapter, we have discussed this contradiction in Para 31(k): the conviction that social media networking sites and the web have become a new public interaction platform. Hence, it could be regarded as a public space. As compared to the traditional interaction, these web-based interactions are irrelevant and outmoded sometimes. Cf. Para 20: mentions that public spaces are designing means to consider some alternative $\mathrm{s}$ and modern steps based on modern communication techniques and urbanized usage.

On the physical public space, the main focus is kept on the ToolKit as it is likely to dwell on the physical and nonplanned intersection between the public spaces and the way these both provide support to each other.

The physical web supports and boosts the people's movement and stationing and offers the means of transportation from which the city validity depends.

Inside the fixed premises, public venues, the host market, and accessible commercial activities occur whereby the City's social and economic dimensions are illustrated. They offer a lot of new and latest recreation ideas, exercises, and physical workouts. This way, this allows the regeneration of gardens and parks and other sporting facilities for the public. Besides, they also help promote the cultural aspects and education with the help of some public spaces such as libraries and museums.

The people, along with their collective memories, are the places whereby the people's identity is shown and mirrored, and sustenance is found; this is when they acknowledge the fact that they are a part of a particular community.

- Enhancement of encounters, freedom of expression, as well as friendliness.

- These are the meaningful urban architecture part and integral aspects for landscape with a crucial role in the determination of the City's overall image.

The features mentioned above also indicate some significant rules and principles available to administrations of public places, and they build integrated policies based on these features. In the functional upgrading of the urban fabric and social and economic regeneration, they play their role in a broad range of urbanized planning and morphological development. 


\section{vi) Evaluating Public Space:}

The urban designing level is considered with the help of some features that help the evaluation of the spaces existing at present. These features help design the latest models:

Size:

Shape:

Diversity

Accessibility:

Participation\& Modification:

Facilities for pedestrians:

Traffic

Management:

Security:
The scale decides how many people would vote in and participate in different political events and affect their performance. As in the maximum number of persons who can occupy space, the total carrying capacity of urban space is therefore important to calculate.

The way people perceive, and experience space determines how it is. It also affects the visual and acoustic contact that people can make in space.

Democratic urban areas require a balanced and controlled mix of user groups and activities to allow users from different backgrounds to coexist and carry out similar activities without a dominant group.

The availability of a common urban area refers to all the necessary elements that promote safe mobility (e.g., ramps, troughs, audible and visual signs).

Refer to community engagement (as far as possible) in urban planning and change.

It is an essential component that is always used in all public space democracy proposals. Considerable Research and literature have shown that traffic control relates to the connection or unbundling of public space. The efficiency of use, access, and participation in space is also affected by traffic management.

It is an essential component that is always used in all public space democracy proposals. Considerable Research and literature have shown that traffic control relates to the connection or unbundling of public space. The efficiency of use, access, and participation in space is also affected by traffic management.

This applies to aspects of public security and a sense of protection, such as police existence and "natural surveillance," meaning areas with many people in motion and good space visibility.
Comfort:

To be democratic, an urban space must be relaxed. This ensures ample shade, parking, sidewalks, public transport with bus stops, parks, bike paths, etc.

Visual and Some of the elements influence urban Aesthetic character, including seats, hard and soft Elements: landscaping, paving, plantation (natural factors), street furnishings, shelters, and protection (microclimates).

vii) Public spaces - (re)defined.

Thus, it is difficult to define the public domain as a place. Many types of public space -quite varied on the face of it. So, it is misleading that something is called the public space as it stands. With all forms of qualifications, the public spaces are those where we move around and interact with other people. The public places are an abstract ideology covering the fields where everyone agrees to interact.

- As urban civility banners the use of public spaces

- These public spaces also serve as the urban commons

- Income, investment, and creation of wealth or revenue is promoted with the help of these public spaces

- The environmental sustainability is enhanced as well by these public spaces

- These urban public spaces are likely to have a significant impact on transport efficiency.

- Public health is also improved with the help of these public spaces

- These public places ensure urban safety.

- Public spaces promote equity and social inclusions.

- The public places promote age-friendly and gender friendly environment

- The use of these public spaces promotes citizen involvement in city affairs

- Public spaces are the keys to make great cities.

\section{InTERnational, REgional \& GLOBAL PraCtices:}

\section{A UN Global Public Space Toolkit:}

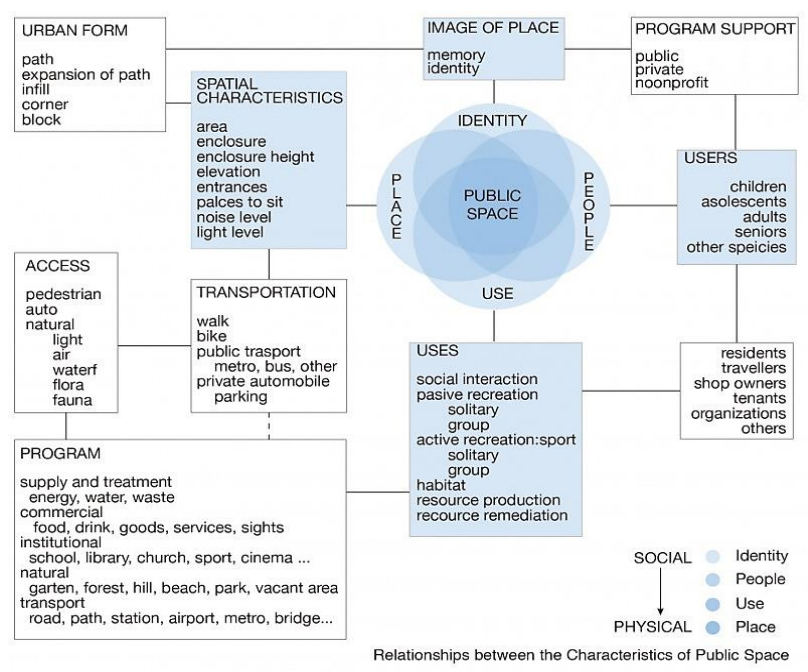

Figure 6. relationships between the characteristics of public spaces 
The user-friendly guide for cities is made available with the help of this global public space Toolkit, especially in areas where there are higher growth rates of demographics and limited financial resources. This space kit has been launched with institutional partners, and the UN habitat partners with some creative and highly efficient, and workable ideas and solutions are determined. The ways are determined, which could improve the availability and quality and uniform distribution of good and well-maintained public spaces. For the cities to give concrete guidelines and superb policies, this Toolkit will be a practical reference. It can also help make various developmental plans for the public spaces in the cities.

In 2011 the program of Global Public Space was launched, and the main aim behind it was to enhance the quality of the public spaces and improve them all across the globe. In most cases, we have seen that city administrator tend to neglect public spaces until now undervalued. They are now days becoming the cities' backbone. The pleasant and easily accessible sites to all the people of a town are known as public spaces. These are not designed to make any profit; instead, the aim is to facilitate public interaction, especially in the parks, sidewalks or pavements, playgrounds, and markets. These public spaces strengthen the community's cohesion if they are nicely maintained. They are likely to positively impact the social well-being, health, and happiness of the people in the cities.

It also helps cities to encourage a higher population densityan essential part of future sustainable cities. The program, which includes Bangladesh, India, Kenya, South Africa, Peru, Haiti, Kosovo, and Mexico, operates in more than 20 countries. This program focuses mainly on cities with a high population in informal settlements in developing countries. The key partners are cities and municipal governments that are routinely responsible for building and managing local public spaces.

\section{B Public space projects on the ground.}

For this program, the significant component in collaboration with local government bodies is the quality of public spaces' construction and design. These physical spaces serve the public spaces all across the cities, and hence the local bodies' capacity is improved so that communities can interact with each other in the long run. The UN habitat financed two public spaces projects in Nairobi, for example, from Nairobi city's country government.

The local government made the country's undertaking to improve as many as sixty public places without any funding from the United Nations' habitat for the undergoing projects. The local authorities are needed to find suitable places for these public areas and clarify ownership rights. They also need to find out the way these spaces are likely to have an impact on citywide. The public space administrators are supposed to engage the democratic and particular public spaces with ideal and attractive designs and add people's involvement to boost up the communities' interaction in these public places.

\section{The Network on Public Space.}

To have a proper implementation of the projects regarding public spaces and impact the public spaces and global debates around these spaces, a Network on Public space was established by UN habitat. A wide range of organizations is included in this network from all across the globe. They are seriously putting their efforts to reduce the problems regarding the availability and accessibility of public spaces. These administrators' normative work involves tools development, highlighters, guidelines of policies, and functional tasks for the safer implementation of these projects in public places.

\section{Cairo case as the Research focus.}

In the aftermath of the revolutions on January 25th and June 30th, 2013, Egypt looked towards the reform and reconstruction of modern Egypt in a revolutionary social and political mobility context. To find an excellent interface between urban space and politics, a call for "Democratic Urban Space Design" has been put in motion and concerns user rights, freedom of access, or freedom of action in public places.

There are both old and new, bright, and challenging links between urban space and politics. This is a subject which in the Arab world, in general, and in Egypt, has scarcely been touched upon.

\section{A Urban space and political life.}

Political theorists talk about urban areas as a meeting point between people in a community capable of containing their differences. It is an area of moral convergence that incorporates shared values that allow people to take part in collective deliberations, decisions, and actions. The contemporary urban practices have not understood the real value and vitality of public spaces in most Arab and Egyptian cities. The function of communications between persons is almost planned for urban public areas. For a very lengthy period, governments have tried to keep people away from government spaces, to abort public life, to dry channels that can contain intense pulse in the City, and to turn those spaces only as corridors of traffic, which almost have no available seats. This conflict prioritized "political urban planning" science and practice when democracy is recognized in urban areas based on the maximum limitations that the City can afford to its inhabitants politically.

The recent wave of political change across the Arab world underlines the need to re-understand the role of politics and how this will affect urban spaces' design. Therefore, the transformations of urban Space in Egypt as the basis for future innovation need to be reread. In the context of the power shifting from dictatorship to democracy, from more power to the government, it needs to be reproduced to more power to the populace.

Politics governs how public spaces look in Egypt. The government has introduced laws and policies that restrict Egyptians ' access to public space - places where people meet, 
discuss, talk, and even demonstrate or protest. Urban spaces that people could use to collect and demonstrate were divided or systemically closed. This strategy does affect not only public areas but also urban areas and contributes to urban regeneration.

B The Voice of People: January 25th. Revolution: From Virtual Space to Urban Space
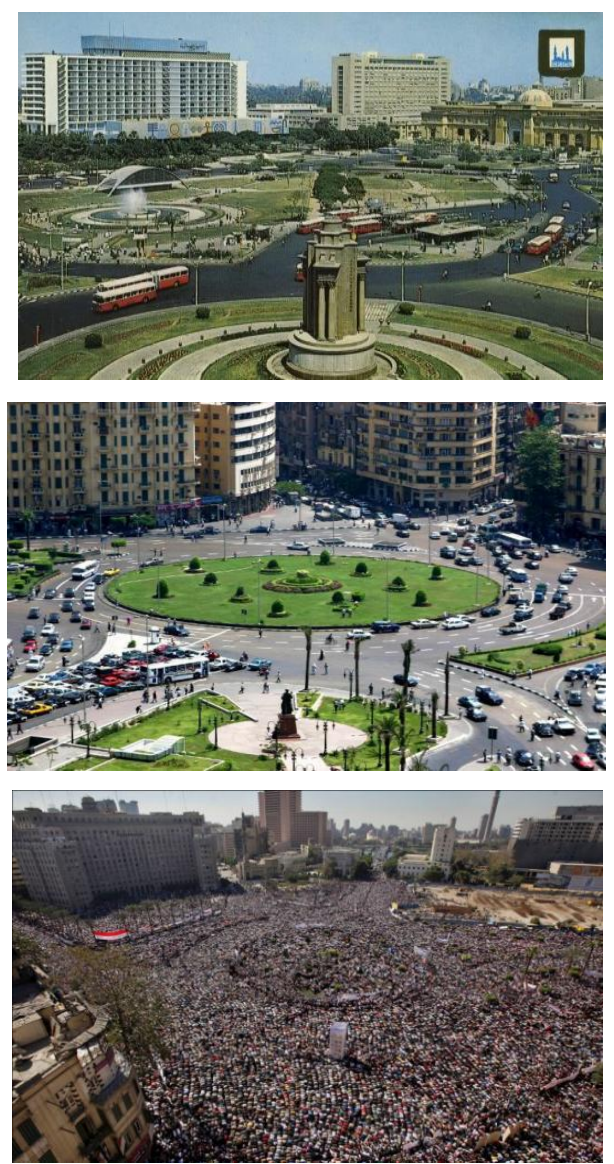

Figure 4, Tahrir square witnessed the January 25th Revolution in 2011.

Millions of Egyptians set out for "food, freedom and social fairness" on January 25th, 2011. Tahir Square, the 18-day sit-in, or ' Midan,. 'began in Egypt in social networking sites in virtual public spaces that played a crucial role in the coordination and mobilization of activist groups. The virtual space became the "last free space" for those activists, expressing their views that everyone had become a sender, recipient, and active partner in decision - making. The January Revolution reinforces the physical relationship between man and Place. Nothing would change without the presence of an urban "real space" as the tool for pressure, despite the power of the social media in this revolution. There is no distinction between the "virtual spaces" from the actual physical spaces. Tahrir Square is essential because it is very close to many government buildings. Therefore, Tahrir's takeover would be a confrontation among protesters and symbols of the state's formal authority. The high visibility where the mass congregation within a circular space would create an image of intensity and advantages is another essential aspect of this space.

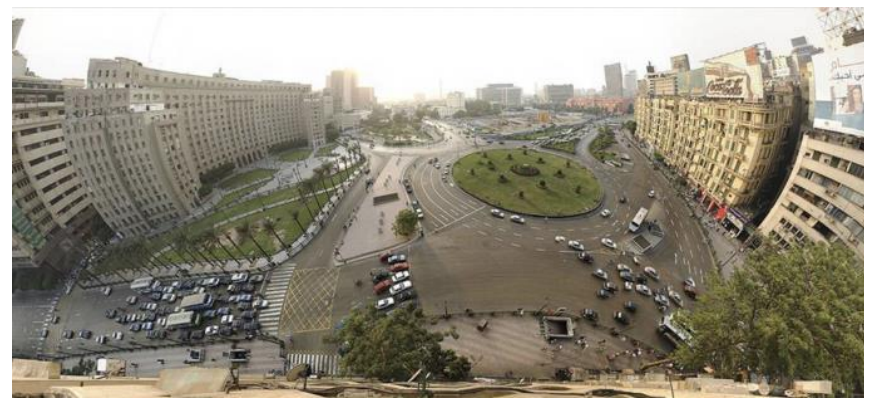

Figure 5. Tahrir Square in Cairo's most important public space.

(Attia, S.2011)

Tahrir Square's image is widely broadcast in the international media, inspiring many Western mobilizations and generating a wave of what is known as "Occupy the public space." This is evident from student activists in the UK attempting to occupy Trafalgar Square in London for 24 hours and turn it into Tahrir Square. More recently, the new "Occupy" campaign has taken the picture that several public spaces are being turned into a "Tahrir Square" Figure (5).

\section{(i) The decline of Public Spaces in Cairo.}

In society, public space plays a significant role. The typical Cairo image is an overcrowded city, with a high building density and high pollution. In their lives, people long for change. Public space offers the community an opportunity to alleviate the stresses caused by the City's heavily densely populated population, such as unemployment, low wages, poorness, and so on. Public space serves the community and is affected by historical, cultural, and social aspects. "When we can resolve this problem, we have reached a solution that solves major social issues," says Omar Nagati, architect and urban planner: "public space unites all people: men and women, Muslims and Christians, the elderly and young, liberals and conservatives, the rich and the poor, etc.

This decrease in social segregation at all levels on the banks of the Cairo river, residential communities, public gardens, and public squares impacts the production of successful sites. These occurrences result, through the development of the individual entities and the imposition of behavioral patterns in urban space, of a rigid ontogenetic approach. Good design is often overlooked and over-imported by particular social groups' requirements to control decision-making, incorporate political, economic, or social significance while encouraging and enabling natural social spaces to be produced. The street patterns and space and physical and social elements that makeup borders between privately - owned and public spaces reflect this in no small part. In the privatization of waterfronts, this increased social inequality often takes shape. Therefore, the Nile River is used by private bodies, high-end restaurants, clubs, and water boats as it is one of the essential factors in Cairo's urban landscape. Space available to the public in Cairo and Giza is minimal, given the river's length. 


\section{(ii) Public Squares in Cairo.}

The city squares were adorned with fountains, statues, portraits, and other works of art, as was the case in most historical cities (Fig. 2). In contrast, the public space was used for public events, public hearings, and the exchange of goods and services (Madanipour 2003). Particular festivals include Mulids, who celebrate culture and traditions in the Cairo public streets and traditional festivals. However, social unrest has forced such festivities away from significant public places because the intellectuals and affluent communities, who prefer to be isolated from the general public, do not generally support them. Despite these and other festivals with an important cultural tradition, the middle and upper classes regard them as a mess, as people of the bottom class usually lead them. The reality of urban society is based on the social organization's confrontation, as each group is concerned with communicating its social interests through urban meaning (Castells,2003). This thus becomes conflict and a symbolic power struggle. The urban environment, however, tends to represent the dominant class's interest. Simultaneously, other communities are seen as a danger for the public good and are excluded by physical, social, and symbolic barriers from social spaces.

\section{(iii) Public Parks in Cairo.}

Most gardens are still closed and unused, while other gardens require an entry fee, which cannot be paid by all of the poor. Many parks have neither seats nor banks nor playing fields. The government has ignored public areas, but they encourage closed communities, private parks with playgrounds, and shopping centers.

\section{(iv) Urban Challenges are facing Public Spaces in Cairo.}

Many problems are there in the creation and maintenance of public spaces; the biggest concern is ownership. We are likely to see very few buildings in cities like Cairo, which are registered lawfully, especially in the sparse surroundings where the top of roofs is used to get benefits like storage areas or small farms. To decide who should be given the right to work at the rooftop is not an easy matter. In Cairo, especially across the weaker areas of the City, there is a lack of registration of electricity meters under the owners' name. For water meters, the standard forms are used, and as a result of it, all the residents of a particular building can irrigate and harvest the crops at the building's rooftop. The structure of buildings is another significant concern. Mostly below average construction of buildings is seen and this is a matter of massive concern whether some extra weight can be supported by these buildings at the rooftops and especially if there is a farm at the top of them, can it bear the leakage of water which is likely to happen anytime. The residents have to pay some costs so that at the rooftop, the proper system of gardening can be launched. According to some of the leading economical and financial investigations, the cost of this installation ranges from 7,000 to 15,000 LE.

\section{CONCLUSIONS:}

Many public spaces that are an integral part of our daily life; are considered a crucial part of city life. The places where the kids play, the roads we use to reach schools or workplaces, the sports parks in the locality where we sit and play, the parks where we enjoy walks and lunch, etc. We will see much publicity around us, and the public space could be termed as our outdoor living room. Cities are more and more separated when the public spaces are lacking, insufficiently available, and designed poorly; in the same way, privatized public spaces aren't considered successful. Some lines are drawn based on religion, race, financial status, etc. The increasingly segregated cities are the outcomes of it. In such conditions, there is always a risk of increasing social tensions, social mobility, and financial opportunities are restricted as well.

There has been an emergence of a new paradigm that understands a failure in market-led growth to make up and preserve the open spaces, either public or private. There is a mutual reinforcement of these components, and this is important to ensure that the prosperous cities have undergone development. They have vibrant streets and a lot of attractive and nicely maintained public spaces:

- There is a need for rules and proper legislation to ensure that access to all these public spaces stays protected.

- To offer adequate amount, quantity and good quality public spaces, urban planning and designing is needed

- For sharing value, there is always a need for urban financing and economy to share values for promoting income, revenues, investment, production, and offering better job opportunities.

\section{Suitable public spaces can play a decisive role in this regard by:}

Permitting sound turn of events (i.e., road matrices), drawing in the venture, uses, exercises, and improving security accordingly. Expanding property estimations for producing extra city income can be used. Giving occasions to monetary cooperation and subsequently upgraded work openings contributes to a city's social, verifiable, and engineering gift, consequently improving metropolitan appeal and advancing the travel industry.

Given the number of factors inside the metropolitan climate and the multifaceted nature of the City, it can't be asserted that the use of these arrangements and standards and their strategies will ensure a maintainable metropolitan turn of events. In any case, they will go far in limiting the odds of defining an awful plan and setting a plan for public space that will give the individuals the ideal possibility of making the most of their environmental factors as people and as individuals from the network.

Precisely, public spaces' capacity as advertisers of value ought to go far in producing eagerness, responsibility, the solidarity of direction, and hearty conveyance. Lamentably, what is correct isn't secure. For instance, the Toolkit records the numerous requirements that urban areas experience in seeking after the objective of improving the amount, quality, and 
circulation of public spaces in our urban communities and towns.

A portion of these requirements can be taken out by putting resources into public space creation, the board, and use. Others, similar to the ever-present danger to assume control over open spaces for private addition, industrious mistakes in plan and the executives, successive protection from put resources into participatory practices, or the expanding commercialization deappearance of social association, require our ongoing cautiousness.

When we consider public spaces, our brains go to parks, gardens, and playgrounds. Much as these extraordinary highlights of our day by day metropolitan life are authentic and necessary public spaces. This Toolkit goes past the element of individual metropolitan components and positions public spaces in the part of heroes of the metropolitan turn of events. This is the reason, in the central aspect of this Toolkit, the ideas of "public space-drove metropolitan turn of events," of arranging public space as a framework, of the round connection between making, keeping up, and getting a charge out of open space, of imagining investment itself as a "virtual public space" where all can communicate on an equal balance, and of the significance of public space systems for asset poor and quickly developing urban areas are introduced. The idea of public spaces as a framework is fortified by straightforward proposals for rudimentary citywide overviews and markers to survey public spaces' nature and check progress around there.

One extraordinary notice concerning our case for a more extensive, less ordinary perspective on open space is the road's function. The road is characterized in this investigation as the public space second to none since it is the most unavoidable, flexible, and versatile public space of all. One pivotal Perspective is also the part of the road as the appointing component of the physical metropolitan turn of events. In a perfect world, roads are arranged and worked before structures are, and subsequently comprise an imperative apparatus in possession of organizers and neighborhood governments to imagine and advance maintainable and systematic metropolitan development.

For this Toolkit, another strong claim is that various strategic development and policymaking are only good since they are based on various ideas and principles. They firmly stand on these principles. The simple and classification of public spaces should be defined precisely, and these public spaces are divided into private and publicly owned spaces. Simultaneously, various other principles deviate from reality, and they are only restricted usage. The principles are drawn in the end for this Toolkit, and in the most recent times, it has been a comprehensive statement based on the topic and charter of public space. These are also subjected to the latest experiences and reasonable practices in an urban context and various regions. Exciting and inspiring reading can be offered by this Toolkit as expected, and it will somehow strengthen our feeling and believe that we can do least as in the past by those who have already done it before.

Tahrir Square is the Place where the revolution of January 25th started, and by June 2013, the revolution continued. It also demonstrates the ways to construct and use urban spaces. Urban spaces have gained another meaning in the past few years, and people's voices are essential in designing public spaces.

To develop the urban areas representing the healthy relationship between urban and political design, the state is supposed to create a clear and comprehensive vision of this Place, and these places are also known as democratic places. For urban development, a comprehensive vision is needed to be implemented. There is a need to carry out this democratic process that includes all the stakeholders' communities to shape these public spaces. For these public spaces, urban designers should acknowledge that social, economic, and political forces are needed to produce suitable urban spaces that are not designed specially. With time, these are changing.

\section{Suggested Guidelines of public spaces}

According to such Perspective, some guidelines can be portrayed while discussing the social impacts on public spaces:

\section{Physical Guidelines:}

Providing a suitable environment for the users to practice their various socio-cultural activities and supporting such users' experiences to encourage people to spend more time within such spaces, reflecting on the physical quality of space, dimensions, proportions, components, green areas, \&furniture.

\section{Legal Guidelines:}

Through wise management of such public spaces, in a way that respects the right of people to use such spaces, maintaining a healthy environment, meanwhile monitoring any illegal practices, or other types of practices that negatively affect such spaces, whether physically or by other means relevant to the socio-cultural values of the local community.

\section{Guidelines related to equality:}

Making these public spaces accessible to all community members, regardless of their socio-economic level or standard, religion, gender, or color.

\section{RECOMMENDATIONS:}

Scientific Research is needed at all times, and further investigative steps are to be taken to have explicit knowledge about the better designing and maintenance of public spaces. As we have studied in the above discussion that public spaces are too significant if they are maintained nicely and well decorated and play a vital role in the attraction of public to make investments, there are plenty of uses of these public spaces, the people of cities can get engaged in many activities, this ultimately improves the security of the nearby towns and increase more value to the properties. These public spaces are also means of generating finances locally and to create some economic connection opportunities for the enhancement of living standards. The creation of public spaces, the conservation, designing, management, and the proper utilization of these public spaces need perfect local governing bodies, and inhabitants are supposed to share their burden and work individually for the community's betterment. To offer the good debates and arguments, this investigative work has achieved its primary objective; it also explains the ethical principles and reasonable examples to those who believe that public places are needed more at the center of the cities' urban 
agenda. The main aim is the conviction of this into reality. The highlighted public spaces are offered in this argument as the urban civility banners. They promote equity, urban commons, and their embodiment; they act as the markers of great cities and result in the public's involvement. In this way, the public spaces enhance the sustainability of the environment and create much revenue.

The research recommendations could be categorized as follows:

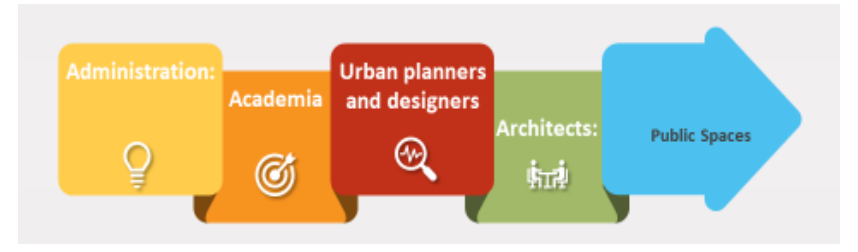

Administration: The local governments need to take some unique trans-disciplinary way for the public spaces, and this can be done by working with stakeholders and organizations of various disciplines. These organizations and stakeholders include civil societies, academia, and the private sectors to ensure that public spaces are safe and easily accessible to the public.

Academia: further investigative work is needed to find out the public spaces and their technical components rather than some other ideas leading to some natural and straightforward approaches to deal with public spaces. Some parameters are needed to be kept under check, such as physical, economic, environmental, and social factors allowing the city authorities to develop and expand the public spaces around the cities and city centers to make the urban life better.

Architects: the concept of the public space can be explored a lot more by integrating the public areas in the designing process of the cities, especially when designing the surroundings of any building, whether these buildings are private or public. Along with this, the details are needed to be further investigated so that the concept of these public spaces is made feasible, and cities are added with more value.

Urban planners and designers: In this concern, the individual projects can be encouraged inside the network of some other local projects for the City's urban throughput. One can achieve long term and short-term benefits by using this technique.

\section{AUTHORS CONTRIBUTION}

1- Conception or design of the work 50/50

2- Data collection and tools 50/50

3- Data analysis and interpretation 60/40

4- Funding acquisition 40/60

5- Investigation 40/60

6- Methodology 50/50

7- Project administration 60/40

8- Resources 50/50

9- Software 60/40

10- Supervision $40 / 60$

11- Drafting the article 50/50
12- Critical revision of the article. 50/50

13- Final approval of the version to be published 50/50

The corresponding author is responsible for ensuring that the descriptions are accurate and agreed upon by all authors.

\section{REFERENCES.}

[1] Aesop-planning.eu. (2016). Public Spaces and Urban Cultures - AESOP. [online] Available at: http://www.aesop-planning.eu/blogs/en_GB/urbancultures-and-public-spaces [Accessed 10 Jan. 2016].

[2] American Planning Association. (, 2016). Characteristics and Guidelines of Great Public Spaces. [online] Available at: https://www.planning.org/greatplaces/spaces/characteristics.htm [Accessed 17 Jan 2016].

[3] Attia, S. (2011). Rethinking Public Spaces in Cairo. [online] Available at: http://www.cpasegypt.com/pdf/Sahar_Attia/Rethinking\%20Public\%20Space\%20in\%20 Cairo.pdf [Accessed 12 Mar. 2016].

[4] Attia, S., Shafik, Z., El Halafawy, A., \& Khalil, H. A. (2017). Urban Regeneration of Public Space - Al-Alfi Street - Downtown Cairo. International Journal of Sustainable Development and Planning, 12(04), 808-818. https://doi.org/10.2495/SDP-V12-N4-808-818

[5] Brandão, A., and Brandão, P. (2017). Public Space, Infrastructure, Landscape: an interdisciplinary matrix for urban spatial continuity.

[6] Coelho, R. (2016). Designing the City from public space. A contribution to (re)think the urbanistic role of public space in the contemporary enlarged City. [online] Journalpublicspace.org. Available at: https://www.journalpublicspace.org/article/view/53/45 [Accessed 4 Feb 2016].

[7] Geeva Chandana (2020) 'Solids and voids an analysis of need for open space'. Available at: https://www.slideshare.net/GeevaChandana/solidsand-voids-an-analysis-of-need-for-open-space (Accessed: 16 June 2020).

[8] Manuel Castells, The Network Society. From Knowledge to Policy, 2003, available https://www.researchgate.net/publication/301788885_The_Network_So ciety_From_Knowledge_to_Policy

[9] Gsd.harvard.edu. (, 2016). Putting Public Space in its Place," Harvard GSD Conference on Public Space - Harvard Graduate School of Design. [online] Available at: http://www.gsd.harvard.edu/event/putting-publicspace-in-its-place-harvard-gsd-conference-on-public-space/ [Accessed $31 \mathrm{Feb} .2016]$.

[10] Ingentaconnect.com. (, 2016). Public Space and Urban Justice: Ingenta Connect. [online] Available at: http://www.ingentaconnect.com/contentone/alex/benv/2016/00000043/0 0000002/art00001 [Accessed 26 Jan. 2016].

[11] JRF. (, 2007). The social value of public spaces. [online] Available at https://www.jrf.org.uk/report/social-value-public-spaces [Accessed June 21st. 2016].

[12] Stroud, S., Ibrahim, B., Youth Activism, and Public Space in Egypt, The American University in Cairo (AUC) Press, 2011.

[13] Rabbat, N., "The Arab Revolution Takes Back the Public Space.", University of Chicago Press, 2013.

[14] Ravazzoli, E., Rethinking Public Space in Cairo, ArcDuoCitta, 2011.

[15] Taha, Dalia A. (2016) Political Role of Urban Space Reflections on the Current and Future Scene in Cairo-Egypt Architecture Research 2016, 6(2): $38-44$

[16] UN-Habitat. (, 2017). Annual Report 2016: Global Public Space Programme by UN-HABITAT. [online] Available at: https://unhabitat.org/books/annual-report-2016-global-public-spaceprogramme/ [Accessed 19 May 2016].

[17] What Happened to Public Space? A Quick Guide Through Europe's History. (2017, March 25). Arch2O.Com. https://www.arch2o.com/happened-public-space-quick-guide-europeshistory/

Title Arabic:

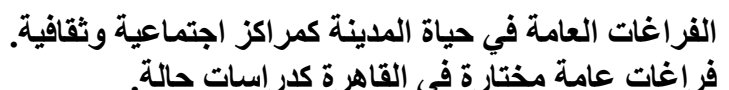




\section{Arabic Abstract:}

تلعب الفراغات العامة دورا متزايد الأهمية في العديد من الدول، ومن هذا

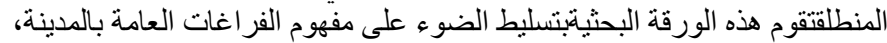

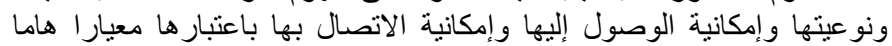

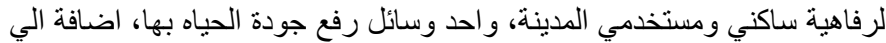

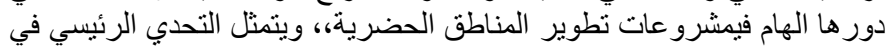

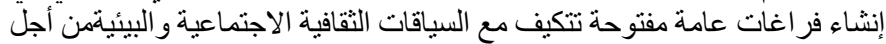

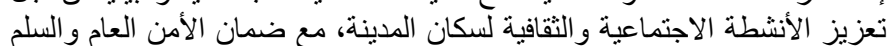

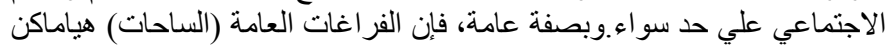

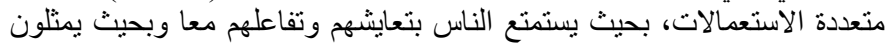

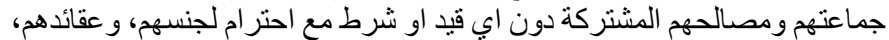

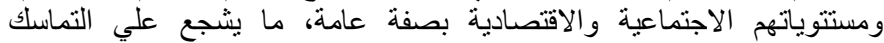

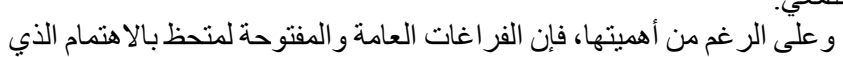

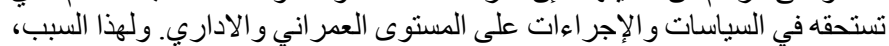

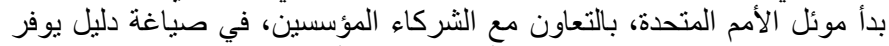

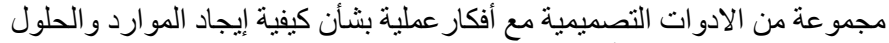

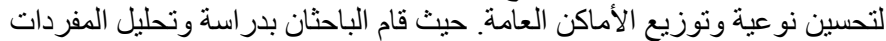

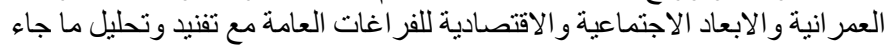

بالدليل المشار البه للوقوف علي ما يمكن اعتبارة مبادئ يمكن اتباعها و البناء عليها

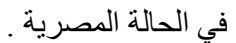
وقد افرد البحث الدراسة التفصيلية لحالة القاهرة لما تتسم به المدينة من مكانة

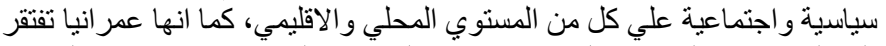

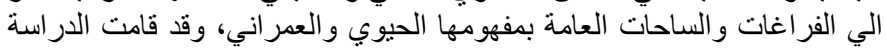

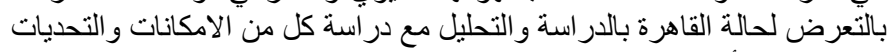

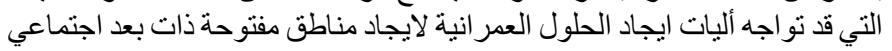

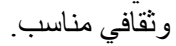

و فقا لهذا المنظور يمكن تصور بعض الضوابط التي يجب ان يتم مر اعاتها عند التهي

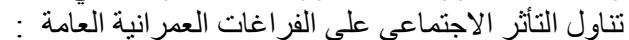

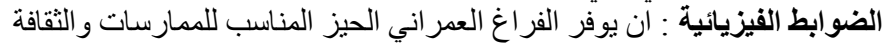

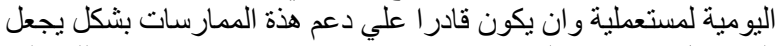

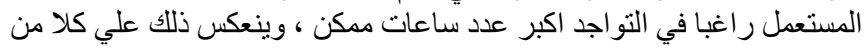

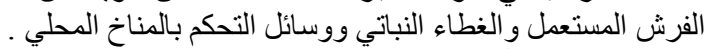

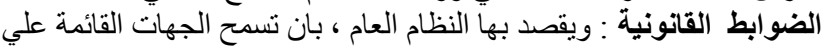

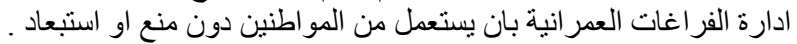

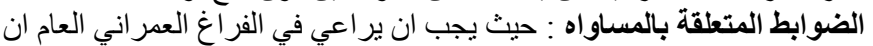

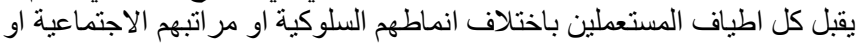

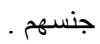

